\title{
GAMBARAN TINGKAT PENGETAHUAN PASIEN GASTRITIS TERHADAP SWAMEDIKASI DAN RASIONALITAS OBAT DI APOTEK KELURAHAN MENDAWAI KOTA PANGKALAN BUN
}

\author{
Mustika antik wibawa ${ }^{\mathbf{1}}$;Poppy Dwi Citra Jaluri ${ }^{\mathbf{2}}$ Fakhruddin $^{3}$ \\ ${ }^{1,2,3}$ STIKes Borneo Cendekia Medika Pangkalan Bun \\ ${ }^{1}$ Email : $\underline{\text { m.antik.wibawa@gmail.com }}$
}

\begin{abstract}
ABSTRAK
Swamedikasi adalah upaya seseorang untuk mengobati penyakit atau gejala ringan tanpa resep dokter.Keterbatasan pengetahuan masyarakat tentang obat, penggunaan obat, serta penyimpanan obat merupakan penyebab terjadinya kesalahan dalam swamedikasi.Tujuan penelitian ini untuk mengetahui tingkat pengetahuan masyarakat tentang swamedikasi dalam penggunaan obat yang rasional pada penyakit gastritis.Penelitian ini menggunakan metode observasional analitikdengan sampel penelitian pada pasien gastritis yang akan melakukan swamedikasi sebanyak 207 responden berusia 18-49 tahun yang dipilih dengan metode consecuative sampling dari 3 apotek di kelurahan mendawai. Pengambilan data dilakukan melalui pengisian kuesioner yang telah di uji validitas. Data dianalisis dengan uji Chis-quare menggunakan Statistical Product And Servicer Solution (SPSS).Hasil penelitian menunjukanbahwa tingkat pengetahuan responden tentang swamedikasi gastritis di tiga apotek $(87,0 \%)$ tergolong baik, $(10,1 \%)$ tergolong cukup dan $(2,9 \%)$ tergolong kurang. Untuk penggunaan obat swamedikasi gastritis $(94,2 \%)$ responden menggunakan obat secara rasional dan $(2,4 \%)$ tidak rasional. Berdasarkan hasil uji Chis-quaretingkat pengetahuan swamedikasi gastritis terhadap rasionalitas didapatkan nilai $p$ value $(0,057)>$ alpha $(0,05)$.Hasil penelitian ini dapat disimpulkan bahwa tingkat pengetahuan responden tidak berpengaruh terhadap rasionalitas penggunaan obat.
\end{abstract}

Kata Kunci :Swamedikasi, Apotek, Pengetahuan, Rasionalitas penggunaan obat, Pangkalan Bun.

\begin{abstract}
Swamedication is defined as the usage of drugs to treat an illness without doctors' prescription. An error in swamedication can happen due to the limitation of the public knowledge about medicine, medicine use, and medicine storage. This study aimed to find out the patients' gastritis knowledge level about swamedication and drug rationality. This study used an analytical observational method. The samples of the study were 207 gastritis patients (18-49 years old) who were going to do swamedication. The samples were chosen by using consecuative sampling method from three pharmacies in Mendawai, Pangkalan Bun. The data were collectedby using the questioners that had been tested for the validity. Then, the data were analyzed by using Chi-square test using Statistical Product and Servicer Solution (SPSS).The results of the study showed that the respondents' knowledge level about gastritis Swamedication in three pharmacies were good $(87.0 \%)$, enough (10.1\%), and less $(2.9 \%)$. It was also found that the respondents' were used grastitis swamediacation rationally (94.2\%) and irrationally (2.4\%).Based on the results of Chi-Square test, the level of knowledge of gastritis swamedication on rationality was obtained $p$ value (0.057)> alpha (0.05).The result of the study concluded that the respondents' level of knowledge had no effect on the rationality of medicines use.
\end{abstract}

Keywords : Swamedication, pharmacies, knowledge, rationality of drug use, pangkalan bun 


\section{PENDAHULUAN}

Menurut World Health Organization (WHO) Swamedikasi merupakan tindakan pemilihan dan penggunaan obat seperti obat sintetis, herbal, maupun obat tradisional oleh seorang individu untuk mengatasi penyakit atau gejala penyakit.

\section{Swamedikasi}

biasanya

dilakukan untuk mengobati gejala ringan seperi demam, nyeri, pusing, batuk, influenza, sakit maag, kecacingan, diare, penyakit kulit dan lainnya (Harahap, 2017).

Menurut data Badan Pusat Statistik tahun 2017 mencatat $69,43 \%$ penduduk Indonesia melakukan swamedikasi dibandingkan dengan penduduk yang berobat jalan hanya $46,32 \%$, yang meningkat dari tahun 2016 (BPS, 2017).

Gastritis atau yang secara umum dikenal dengan istilah "maag" atau sakit ulu hati ialah peradangan pada dinding lambung terutama pada selaput lender lambung. Gastritis adalah proses inflamasi atau gangguan kesehatan yang disebabkan oleh faktor iritasi dan infeksi pada mukosa dan submukosa lambung.

Gastritis dapat mengalami kekambuhan dimana kekambuhan yang terjadi pada penderita gastritis dapat dipengaruhi oleh pengaturan pola makan yang tidak baik dan juga dipengaruhi oleh faktor stress (Widiya, 2018).

Berdasarkan angka kejadian pada penyakit gastritis menurut penelitian kesehatan dunia World Health Organization (WHO) mengadakan peninjauan beberapa negara di dunia dan hasil persentase kejadian gastritis yang didapatkan, diantaranya : Inggris sebesar 22\%, China sebesar $31 \%$, Jepang sebesar $14,5 \%$, Kanada sebesar $35 \%$ dan Perancis sebesar $29,5 \%$. Sedangkan persentase angka kejadian gastritis di Indonesia sebesar 40,8\%. Menurut data dari Dinas Kesehatan Kota Pangkalan Bun, penyakit gastritis menempati urutan nomor 4 dari 10 penyakit terbesar di Kota Pangkalan Bun Provinsi Kalimantan Tengah di tahun 2018 kejadian gastritis di Kota Pangkalan Bun tercatat 5755 jiwa.

Berdasarkan uraian latar belakang diatas saya sebagai peneliti tertarik untuk mengetahui tingkat pengetahuan masyarakat tentang swamedikasi penyakit gastritis.Mengingat banyaknya masyarakat tidak mengetahui tentang penyakit gastritis dan penggunaan obat gastritis yang tepat, sehingga sering melakukan swamedikasi tanpa ketepataan obat dan indikasi.Masyarakat yang melakukan swamedikasi dan penyakit gastritis ini memerlukan perhatian khusus saat melakukan swamedikasi di apotek, jika penanganan tidak tepat dapat membahayakan.Diharapkan adanya penelitian ini agar tenaga kesehatan dapat berhati-hati dalam penanganan swamedikasi pada penyakit gastritis dan memberikan informasi-informasi terkait penggunaan obat dan indikasinya, sehingga tercapainya kerasionalan dalam penggunaan obat khususnya pada penyakit gastritis.

\section{METODE PENELITIAN}

Penelitian ini dilakukan dengan cara mengukur terhadap suatu kelompok responden, dengan cara pengambilan data berdasarkan kuesioner. Jenis penelitian ini di 
lakukan secara observasional analitik untuk mencari hubungan antar variabel dengan rancangan cross sectional yaitu jenis penelitian yang menekankan pada waktu bersamaan atau observasi data dalam pengukuran dan pengumpulan data dalam satu waktu bersamaan atau sekaligus (Sani, 2016).

\section{Populasi dan sampel}

Populasi dalam penelitian ini adalah seluruh pengunjung berusia 18-49 tahun yang datang ke apotek di kelurahan mendawai untuk melakukan swamedikasi/pengobatan sendiri.

Sedangkan sampel dalam penelitian ini adalah seluruh pengunjung yang datang ke apotek di kelurahan mendawai dengan usia 1849 tahun yang menderita gastritis dan menggunakan obat gastritis sesuai dengan kriteria inklusi sejumlah 60 pasien di Apotek H.Imam Syafi'i, 75 pasien di Apotek Sehat Jaya dan 72 pasien di Apotek Pondok Sehat.

\section{Kriteria inklusi dan eksklusi}

Kriteria inklusi dalam penelitian ini adalah pasien gastritis dengan usia 18-49 tahun dan melakukan swamedikasi di apotek. Sedangkan kriteria eksklusinya adalah pasien yang tidak termasuk dalam kriteria inklusi penelitian ini.

\section{Pengambilan data}

Sumber data dalam penelitian ini yaitu data primer yang diperoleh secara langsung dari responden melalui pengisian kuesioner. Kuesioner dalam penelitian ini terdiri dari 4 bagian, yaitu bagian pendahuluan untuk mengetahui: apakah pasien pernah melakukan swamedikasi, bagian pengetahuan swamedikasi bertujuan untuk mengetahui tingkat pengetahuan pasien tentang swamedikasi dan penyakit gastritis, bagian rasionalitas penggunaan obat swamedikasi bertujuan untuk mengetahui rasionalitas penggunaan obat gastritis yang digunakan responden danbagian data demografi responden yang bertujuan untuk mengetahui karakteristik responden. Kuesioner yang digunakan sebelumnya dilakukan uji validitas.

\section{Analisis Data}

Tingkat

pengetahuan swamedikasi gastritis dibagi menjadi 4 kategori yaitu tingkat pengetahuan Baik (76-100 \%), Cukup (56-75 \%), Kurang (40-55 \%) dan Tidak baik $(<40 \%)$. Sedangkan rasionalitas di katagorikan menjadi 2 yaitu rasional jika memenuhi 6 kriteria ketepataan penggunaan obat dan tidak rasional jika tidak memenuhi 6 kriteria ketepatan penggunaan obat. Analisis data yang dilakukan melalui 2 tahap, yaitu analisis univariat, digunakan untuk mendapatkan gambaran statistik deskriptif dengan menghitung persentase karakteristik responden yang meliputi tingkat pengetahuan, rasionalitas, jenis kelamin, umur, jenis pekerjaan dan pendidikan terakhir. Analisi bivariat, digunakan untuk mengetahui hubungan tingkat pengetahuan swamedikasi gastritis terhadap rasionalitas menggunakan uji chisquare.

\section{HASIL DAN PEMBAHASAN Karakteristik Responden}

Jumlah seluruh responden sebanyak 207. Berdasarkan hasil 
penelitian, responden didominasi oleh perempuan $(56,5 \%)$ dengan umur antara 40-49 tahun (35,3\%), dan mayoritas pendidikan terakhir SMA $(70,5 \%)$ dengan kategori pekerjaan palingbanyak adalah karyawan (32,9\%). Karakteristik responden dapat dilihat pada tabel 1

Tabel 1. Karakteristik responden

\begin{tabular}{|c|c|c|c|}
\hline Variabe & & $\begin{array}{l}\text { Jumlah (N) } \\
207\end{array}$ & $\begin{array}{l}\text { Persentase } \\
(\%)\end{array}$ \\
\hline \multicolumn{4}{|l|}{ Umur } \\
\hline a. & $18-28$ & 64 & 30,9 \\
\hline b. & $29-39$ & 70 & 33,8 \\
\hline c. & $40-49$ & 73 & 35,3 \\
\hline \multicolumn{4}{|c|}{ Jenis Kelamin } \\
\hline a. & Laki-laki & 90 & 43,5 \\
\hline b. & Perempuan & 117 & 56,5 \\
\hline \multicolumn{4}{|c|}{ Pekerjaan } \\
\hline a. & Tidak/belu & 34 & 16,4 \\
\hline b & m bekerja & 68 & 32,9 \\
\hline $\begin{array}{l}\text { b. } \\
\text { c. }\end{array}$ & $\begin{array}{l}\text { Karyawan } \\
\text { Guru }\end{array}$ & 3 & 1,4 \\
\hline d. & Mahasiswa & 2 & 1,0 \\
\hline e. & Pedagang & 67 & 32,4 \\
\hline f. & Lainnya & 33 & 15,9 \\
\hline \multicolumn{4}{|c|}{ Pendidikan Terakhir } \\
\hline a. & Tidak & & \\
\hline & tamat SD & 2 & 1,0 \\
\hline b. & SD & 14 & 6,8 \\
\hline c. & SMP & 22 & 10,6 \\
\hline d. & SMA & 146 & 70,5 \\
\hline e. & $\begin{array}{l}\text { Perguruan } \\
\text { tinggi }\end{array}$ & 23 & 11,1 \\
\hline Total & & 207 & 100 \\
\hline
\end{tabular}

\section{Sumber Informasi}

Berdasarkan hasil penelitian diketahui bahwa mayoritas responden yang melakukan swamedikasi $(50 \%)$ berdasarkan informasi dari petugas kesehatan seperti dokter, apoteker dan tenaga kefarmasian di apotek, sedangkan (46\%) responden melakukan swamedikasi berdasarkan pengalaman pribadi/ keluarga.

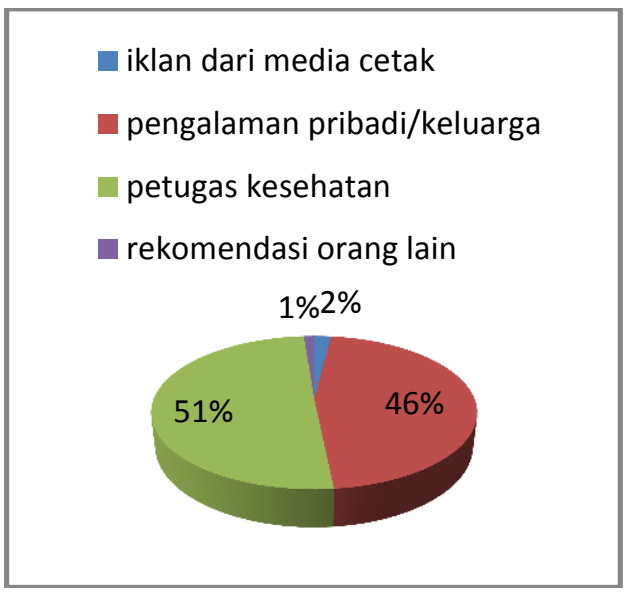

Gambar 1. Sumber informasi

\section{Penggolongan Obat Gastritis}

Hasil penelitian dilapangan menunjukan bahwa penggunaan obat golongan antasida sebanyak 87,9\%, dapat dilihat pada gambar 2 .

Responden mengatakan bahwa obat-obat golongan antasida sebagai pertolongan pertama pada saat penyakit gastritisnya kambuh, jadi harus tersedia obat-obatan golongan antasida dirumah.Penggunaan obat golongan antasida digunakan oleh masyarakat karena obat golongan antasida termasuk first choise pada swamedikasi penyakit gastritis. Menurut penelitian Rizky Vania Okta (2018) obat ranitidine dan antasida merupakan obat antiulcer yang paling banyak digunakan dalam terapi penyakit gastritis. 


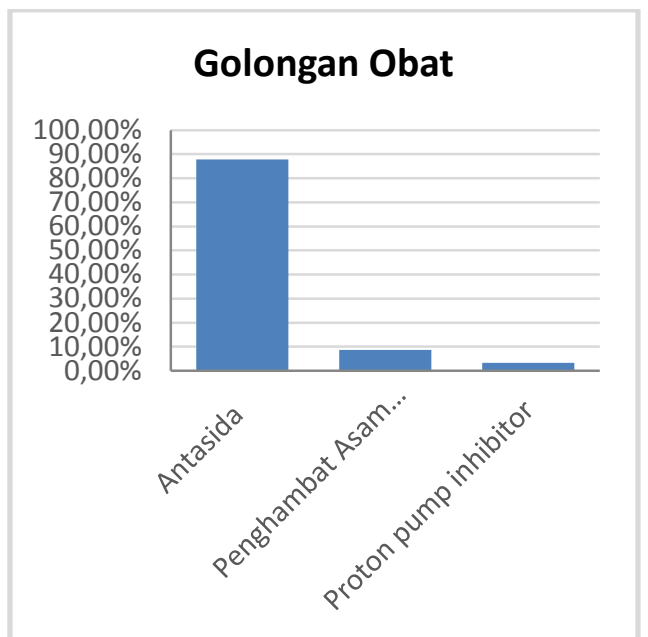

Gambar 2. Penggolongan obat gastritis Tingkat Pengetahuan Tentang Swamedikasi Gastritis

Berdasarkan hasil penilaian responden dari 10 pertanyaan, responden banyak yang menjawab salah pada pertanyaan yaitu : pengertian swamedikasi yang menjawab salah 19,8\%; tanda golongan obat yang menjawab salah $15,9 \%$; penyebab gastritis yang menjawab salah $17,4 \%$ dan nama lain gastritis yang menjawab salah 18,8\%. Dapat dilihat pada tabel 2.

Tabel 2. Pertanyaan tentang pengetahuan swamedikasi gastritis

\begin{tabular}{|c|c|c|c|c|}
\hline \multirow[b]{2}{*}{ No } & \multirow[b]{2}{*}{ Pertanyaan } & \multicolumn{3}{|c|}{ Jawaban } \\
\hline & & $\begin{array}{l}\text { Benar } \\
(\%)\end{array}$ & $\begin{array}{l}\text { Salah } \\
(\%)\end{array}$ & $\begin{array}{l}\text { Tidak } \\
\text { Tahu(\%) }\end{array}$ \\
\hline 1 & $\begin{array}{l}\text { Pengertian } \\
\text { Swamedikasi }\end{array}$ & $\begin{array}{l}157 \\
(75,8)\end{array}$ & $\begin{array}{l}41 \\
(19,8)\end{array}$ & $\begin{array}{l}9 \\
(4,3)\end{array}$ \\
\hline 2 & $\begin{array}{l}\text { Indikasi Penggunaan } \\
\text { Swamedikasi }\end{array}$ & $\begin{array}{l}174 \\
(84,1)\end{array}$ & $\begin{array}{l}19 \\
(9,2)\end{array}$ & $\begin{array}{l}14 \\
(6,8)\end{array}$ \\
\hline 3 & $\begin{array}{ll}\text { Tanda } & \text { Golongan } \\
\text { Obat } & \end{array}$ & $\begin{array}{l}167 \\
(80,7)\end{array}$ & $\begin{array}{l}33 \\
(15,9)\end{array}$ & $\begin{array}{l}7 \\
(3,4)\end{array}$ \\
\hline 4 & $\begin{array}{ll}\text { Pengertian } & \text { Efek } \\
\text { Samping Obat } & \end{array}$ & $\begin{array}{l}195 \\
(94,2)\end{array}$ & $9(4,3)$ & $\begin{array}{l}3 \\
(1,4)\end{array}$ \\
\hline 5 & $\begin{array}{l}\text { Pengertian } \\
\text { Kontraindikasi }\end{array}$ & $\begin{array}{l}193 \\
(93,2)\end{array}$ & $\begin{array}{l}11 \\
(5,3)\end{array}$ & $\begin{array}{l}3 \\
(1,4)\end{array}$ \\
\hline 6 & Penyebab Gastritis & $\begin{array}{l}169 \\
(81,6)\end{array}$ & $\begin{array}{l}36 \\
(17,4)\end{array}$ & $\begin{array}{l}2 \\
(1,0) \\
\end{array}$ \\
\hline 7 & $\begin{array}{l}\text { Makanann Penyebab } \\
\text { Gastritis }\end{array}$ & $\begin{array}{l}193 \\
(93,2)\end{array}$ & $\begin{array}{l}9 \\
(4,3)\end{array}$ & $\begin{array}{l}5 \\
(2,4)\end{array}$ \\
\hline 8 & $\begin{array}{l}\text { Aturan Pakai Obat } \\
\text { Gastritis }\end{array}$ & $\begin{array}{l}192 \\
(92,8)\end{array}$ & $\begin{array}{l}15 \\
(7,2)\end{array}$ & - \\
\hline 9 & Penggunaan Obat & $\begin{array}{l}179 \\
(86,5)\end{array}$ & $\begin{array}{l}23 \\
(11,1)\end{array}$ & $\begin{array}{l}5 \\
(2,4)\end{array}$ \\
\hline 10 & Nama Lain Gastritis & $\begin{array}{l}159 \\
(76,8)\end{array}$ & $\begin{array}{l}39 \\
(18,8)\end{array}$ & $\begin{array}{l}9 \\
(4,3)\end{array}$ \\
\hline
\end{tabular}

Hasil wawancara dengan responden mereka menjawab salah 41 responden dan 9 responden menjawab tidak tahu.Sebagian responden sering melakukan swamedikasi dengan datang keapotek untuk mengobati gejala penyakit ringan yang diderita, tanpa menyadari bahwa telah melakukan swamedikasi.Masyarakat masih sangat awam jika ditanya tentang swamedikasi dikarenakan masyarakat tidak mengetahui kata swamedikasi namun melakukan pengobatan sendiri.

Hasil wawancara dengan responden mereka menjawab salah 33 responden dan 7 responden menjawab tidak tahu.Masyarakat banyak yang mengetahui logo pada obat namun tidak mengetahui arti dari logo obat tersebut. Banyak masyarakat yang paham pada logo (K) itu obat keras dan pemberian obat resep dokter. Ada juga responden yang mengetahui bahwa di kemasan obat ada logo biru atau hijau, namun mereka tidak memahami arti dari tanda/logo warna hijau/biru tersebut.

Hasil wawancara dengan responden mereka menjawab salah 36 responden dan 2 responden menjawab tidak tahu.Masyarakat ada yang mengatakan bahwa mereka telat makan ataupun makan tidak teratur, penyakit gastritis mereka tidak kambuh.Ada juga responden yang mengatakan nyeri pada uluhati pada saat makan tidak teratur.

Hasil wawancara dengan responden mereka menjawab salah 39 responden dan 9 responden menjawab tidak tahu.Masyarakat banyak yang tidak mengetahui padahal responden tersebut sering 
menyebut maag ketika merasakan nyeri uluhati. Masyarakat memang masih awam dengan nama gastritis, yang sering masyarakat kenal seharihari penyakit maag bukan gastritis.

Tabel 3. Tingkat pengetahuan swamedikasi gastritis

\begin{tabular}{l|l|l}
\hline Kriteria & $\mathrm{N}($ Sampel $)$ & Persentase \% \\
\hline Baik & 180 & 87,0 \\
\hline Cukup & 21 & 10,1 \\
\hline Kurang & 6 & 2,9 \\
\hline Tidak baik & 0 & 0 \\
\hline Total & 207 & 100 \\
\hline
\end{tabular}

Berdasarkan hasil penelitian

yang dilakukan di tiga apotek kelurahan medawai dapat diketahui bahwa mayoritas tingkat pengetahuan masyarakat mendawai tergolong baik $(87,0 \%)$. Sedangkan responden tergolong cukup $(10,1 \%)$ dan responden tergolong kurang $(2,9 \%)$.

\section{Rasionalitas Penggunaan Obat Gastritis}

Tabel 4. Kriteria Kerasionalan

\begin{tabular}{|c|c|c|c|c|}
\hline No & Kriteria & Status & Jumlah & $\begin{array}{l}\text { Persentase } \\
(\%)\end{array}$ \\
\hline \multirow{3}{*}{1} & \multirow{3}{*}{$\begin{array}{l}\text { Ketepatan } \\
\text { Pemilihan Obat }\end{array}$} & Tepat & & 99,0 \\
\hline & & Tidak & 200 & 1,0 \\
\hline & & Tepat & & \\
\hline \multirow{3}{*}{2} & \multirow{3}{*}{$\begin{array}{l}\text { Ketepatan Dosis } \\
\text { Obat }\end{array}$} & Tepat & & 99,0 \\
\hline & & Tidak & 200 & \\
\hline & & Tepat & & \\
\hline \multirow[b]{2}{*}{3} & Efek Samping & TidakAda & 205 & 99,0 \\
\hline & Obat & Ada & 2 & 1,0 \\
\hline \multirow{2}{*}{4} & Kontraindikasi & Tidak Ada & 205 & 99,0 \\
\hline & Obat & Ada & 2 & 1,0 \\
\hline \multirow{2}{*}{5} & \multirow{2}{*}{ Interaksi Obat } & Tidak Ada & 204 & 98,6 \\
\hline & & Ada & 3 & 1,4 \\
\hline \multirow{2}{*}{6} & \multirow{2}{*}{ Polifarmasi } & Tidak Ada & 204 & 98,6 \\
\hline & & Ada & 3 & 1,4 \\
\hline
\end{tabular}

Berdasarkan hasil penelitian pada tiap kriteria rasionalitasdapat dilihat pada tabel 4.Sehingga disimpulkan bahwa paling banyak responden mengalami polifarmasi.

Hasil penelitian poin Polifarmasididapatkan $\quad 98,6 \%$ responden tidak terjadi polifarmasi dan $1,4 \%$ responden terjadi polifarmasi. Penentuan dari pertanyaan polifarmasi dilihat dari penggunaan obat pada responden, apakah responden menggunakan obat lain atau menggunakan obat namun memiliki kandungan obat yang sama.

Hasil penelitian menunjukan 3 responden terjadi polifarmasi.Responden masih banyak yang sering menggunakan obat lebih dari satu jenis tanpa memperhatikan kandungan obat tersebut.Salah satunya penggunaan obat promag (kandunganya Hydrotalcite, $\mathrm{Mg}$ hydroxide dan simethicone) bersamaan dengan lambucid (kandungannya $\mathrm{Al}$ hydroxide, $\mathrm{Mg}$ hydroxide dan Simethicone). Responden menggunakan lebih dari 1 obat dengan harapan menggunakan promag dengan lambucid akan mempercepat efek. Ada juga responden yang menggunakan obat ranitidine dan obat antasida yang dapat berpotensi interaksi obat.

Tabel 5. Rasionalitas Penggunaan Obat Swamedikasi

\begin{tabular}{|c|c|c|}
\hline Katagori & N (Sampel) & $\begin{array}{l}\text { Persentase } \\
\%\end{array}$ \\
\hline Rasional & 202 & 97,6 \\
\hline $\begin{array}{l}\text { Tidak } \\
\text { Rasional }\end{array}$ & 5 & 2,4 \\
\hline Total & 207 & 100 \\
\hline
\end{tabular}
disimpulkan bahwa responden di kelurahan mendawai yang menggunakan obat secara rasional 97,6\%. Sedangkan responden yang tidak rasional dalam penggunaan obat gastritis sebanyak $2,4 \%$. 
Pengaruh Tingkat Pengetahuan Terhadap Rasionalitas Obat

Tabel 6. Hubungan Tingkat Pengetahuan Terhadap Rasionalitas

\begin{tabular}{|c|c|c|c|c|}
\hline \multirow{2}{*}{$\begin{array}{l}\text { Tingkat } \\
\text { pengetahuan }\end{array}$} & \multirow{2}{*}{$\begin{array}{l}\text { Jumlah } \\
\text { responden }\end{array}$} & \multicolumn{2}{|c|}{ Rasionalitas } & \multirow[b]{2}{*}{$\mathrm{P}$} \\
\hline & & Rasional & $\begin{array}{l}\text { Tidak } \\
\text { rasional }\end{array}$ & \\
\hline Baik & 180 & 176 & 4 & \multirow{4}{*}{0,057} \\
\hline Cukup & 21 & 21 & 0 & \\
\hline Kurang & 6 & 5 & 1 & \\
\hline Total & 207 & 202 & 5 & \\
\hline
\end{tabular}

bahwa tingkat pengetahuan tidak berpengaruh terhadap rasionalitas penggunaan obat pada responden. Hasil penelitian ini berbeda dengan hasil penelitian Ahmad Irfan (2017) yang menyatakan bahwa tingkat pengetahuan memiliki pengaruh besar terhadap rasionalitas dengan nilai $\mathrm{p}$ value $(0,008)<$ alpha $(0,05)$. Hal ini terjadi dikarenakan adanya pengaruh kondisi masyarakat dan lingkungan tempat penelitian dilakukan.Dilihat juga karena penjelasan apoteker atau tenaga kesehatan di apotek kelurahan mendawai pada saat memberikan obat lengkap dengan informasi obat sehingga masyarakat yang tingkat pengetahuan rendah tetap ada yang menggunakan obat secara rasional.

\section{KESIMPULAN DAN SARAN}

\section{Kesimpulan}

1. Gambaran tingkat pengetahuan tentang swamedikasi gastritis di tiga apotek sebanyak $87,0 \%$ tingkat pengetahuan tergolong baik.

2. Gambaran rasionalitas penggunaan obat gastritis di tiga apotek sebanyak 94,2\% penggunaan obat rasional.

3. Tidak adanya pengaruh tingkat pengetahuan terhadap rasionalitas karena hasil penelitian nilai $\mathrm{p}$ value $(0,057)>$ alpha $(0,05)$.

\section{Saran}

1. Perlu dilakukan penelitian lanjutan di kecamatan lain dengan acuan penyakit ringan lainnya agar tingkat pengetahuan dan rasionalitas swamedikasi di masyarakat dapat terpantau sehingga mengurangi penggunaan obat yang salah pada masyarakat untuk memperbaiki kualitas hidup di masyarakat kota pangkalan bun.

2. Diharapkan kepada masyarakat agar lebih mencari informasi tentang obat-obatan dari sumber yang dapat dipercaya khususnya petugas kesehatan.

3. Diharapkan sebagai tenaga farmasi di apotek khususnya apoteker, dalam memberikan obat disertai dengan informasiinformasi yang mudah dipahami oleh masyarakat, sehingga masyarakat tidak salah dalam penggunaan obat.

\section{DAFTAR PUSTAKA}

Ardiansyah, M. (2012).Medikal bedah untuk mahasiswa. Yokyakarta: Diva Press

Badan Pusat Statistik (2017) Indikator Kesehatan 19951997,Diakses dari : http//www.bps.go.id/ pada 26 Agustus 2018

Brunner and Suddrath.(2002) Buku Ajaran Keperawatan Medikal Bedah, Edisi 8 volume 2.Jakarta : EGC

Departemen Kesehatan RI, (2004) Standar Pelayanan Kefarmasian di Apotek.Jakarta : Departemen Kesehatan RI 
Departemen Kesehatan RI, (2006) Pedoman Penggunaan Obat Bebas Dan Bebas Terbatas. Jakarta : Departemen Kesehatan RI

Departemen Kesehatan RI, (2008) Materi Pelatihan Peningkatan Pengetahuan

Dan Keterampilan Memilih Obat Bagi Tenaga Kesehatan. Jakarta : Departemen Kesehatan RI

Dewi Susanti A, \& Aprillia R, (2018) Penggunaan Obat Rasional (POR) dalam Swamedikasi pada Tenaga Kesehatan di STIKES Sari Mulia Banjarmasin. Jurnal Pharmascience, Vol 05, No 02. Hal 109-116

Gunawan S.G., (2007)Farmakologi dan terapi. Jakarta: Departemen Farmakologi dan Terapeutik Fakultas Kedokteran Universitas Indonesia pp. 210-31

Hermawati, D (2012) Pengaruh Edukasi Terhadap Tingkat Pengetahuan dan Rasionalitas Penggunaan Obat Swamedikasi Pengunjung di Dua Apotek Kecamatan Cimanggis, Depok. Skripsi. Fakultas Matematika dan Ilmu engetahuan Alam Program Studi Farmasi UI

Irma Nurtiana Syafitri, Ika Ratna Hidayati \& Liza Pristianty (2017) Hubungan Tingkat Pengetahuan Terhadap Penggunaan Obat Paracetamol Rasional dalam Swamedikasi. Jurnal Farmasi Dan Ilmu Kefarmasian Indonesia Vol.4 No.1
Keputusan Menteri Kesehatan 1176/MENKES/SK/X/1999 tentang Daftar Obat Wajib Apotek No.3.Jakarta : Departemen Kesehatan RI.

McCance, K.L and S.E Huether, (2006) pathophysiology :The Biologic Basic For Disease in Adults and Children, $5^{\text {th }} e d$., Elseiver Mosby, St. Louis

McQuaid, Kenneth R.( 2013) Obat yang Digunakan dalam Terapi Penyakit Saluran Cerna. Dalam B.G. Katzung, Farmakologi Dasar \& Klinik edisi 12. Diterjemahkan oleh Brahm U. Pendit.Jakarta : Penerbit buku Kedokteran EGC. Hal 1240-1242.

Menteri Kesehatan RI, Keputusan Menteri Kesehatan Republik Indonesia Nomor 347/MENKES/SK/VII/1990 Tentang Obat Wajib Apotek.

Menteri Kesehatan RI, Keputusan Menteri Kesehatan Republik Indonesia Nomor 919/MENKES/PER/X/1993

Tentang Kriteria Obat yang Dapat Diserahkan Tanpa Resep, Jakarta :1993

Menteri Kesehatan RI, Keputusan Menteri Kesehatan Republik Indonesia Nomor 2380/A/SK/VI/83 Tentang Tanda Khusus Untuk Obat Bebas dan Obat Bebas Terbatas, Dit.Jend POM,Jakarta

Mellina, I. (2016). Tingkat Pengetahuan Pasien dan Rasionalitas Swamedikasi di Empat Apotek Kecamatan Medan Marelan.Skripsi. Medan: Fakultas Farmasi Universitas Sumatera Utara. 
Muharni, S., Fina, A. dan Maysharah, M (2015) Gambaran Tenaga Kefarmasian dalam Memberikan Informasi Kepada Pelaku Swamedikasi di Apotek - Apotek Kecamatan Tampan, Pekanbaru.Jurnal Sains Farmasi \& Klinis. 2(1): hal 47 $-53$.

Muttaqin, Arif \& Sari, Kumala (2011) Gangguan Gastrointestinal : Aplikasi Keperawatan Medikal Bedah.Jakarta : Salemba Medika

Nur Aini Harahap, Khairunnisa dan Junita Tanuwijaya (2017) Tingkat Pengetahuan Pasien Dan Rasionalitas Swamedikasi Di Tiga Apotek Kota Penyambungan. Jurnal Sains Dan Klinis.Ikatan Apoteker Indonesia. Sumatra Selatan

Nur Aminatus Sholihah (2019) Efektivitas Biaya Penggunaan Omeprazole Dan Ranitidin Pada Pasien Gastritis. Jurnal kesehatan,kebidanan dan keperawatan. Vol 12 (1)

Nursalam (2013) Metodologi Penelitian : Pendekatan Praktis (Edisi 3). Salemba Medika : Jakarta

Nursalam (2014) Metodologi Penelitian Ilmu Keperawatan.Jakarta : Salemba Medika

Notoatmojo,S.(2003) Ilmu Kesehatan Masyarakat : Prinsip - Prinsip Dasar. Jakarta : PT. Rineka Cipta.

Notoatmojo,S.(2010) Promosi Kesehatan . Jakarta : Rineka Cipta.
Notoatmojo,S.(2010) Metode

Penelitian Kesehatan. Jakarta : Rineka Cipta

Oka, R. V., Kamaluddin and Harahap, D. H. (2018) 'Rasionalitas Penggunaan Ranitidin pada Pasien Gastritis di Puskesmas Alang-alang Lebar Palembang', Majalah Kedokteran Sriwijaya, pp. 2-7.

Pradono, J. dan Sulistyowati, N., (2014). Hubungan antara Tingkat Pendidikan, Pengetahuan Tentang Kesehatan Lingkungan, Perilaku Hidup Sehat dengan Status Kesehatan : Studi Korelasi pada Penduduk Umur 10-24 tahun di Jakarta Pusat. Buletin Penelitian Sistem Kesehatan, 17(1):89-95.

Priyanto, (2009).Farmakoterapi \& Terminologi Medis, Penerbit Lembaga Studi Dan Konsultasi Farmakologi (Leskonfi): Jakarta

Raden Putra, (2013) Aplikasi SIG Untuk Penentuan Daerah Quick Count Pemilihan Kepala Daerah, Cirebon. Jurnal Geodesi Undip, Vol.2, Nomor 4

Rikomah, S. E., (2016) Farmasi Klinik. Edisi I, Yogyakarta : Deepublish

Sani, F (2016) Metodologi Penelitian Farmasi Komunitas dan Eksperimental. Yogyakarta

Sandy E. cinthya, I. S. (2012). Penggunaan Obat Penginduksi Kerusakan Hati Pada Pasien Rawat Iap Penyakit Hati. jurnal farmasi klinik indonesia, 46. 
Supardi, S. \& Notosiswoyo, M. (2006).Pengaruh Penyuluhan Obat Menggunakan Laflet Terhadap Perilaku Pengobatan Sendiri Di Tiga Kelurahan Kota Bogor. Buletin Penelitian Sistem Kesehatan, Vol. 9,4,213-219.

Supardi, S. \& Notosiswoyo, M. (2005).Pengobatan Sendiri Sakit Kepala, Demam, Batuk, Dan Pilek Pada Masyarakat Di Desa Ciwalen, Kecamatan Warungkondang, Kabupaten Cianjur, Jawa Barat. Majalah Ilmu Kefarmasian,134-144.

Suratum \&Lusiana (2010).Asuhan Keperawatan Klien Gangguan Sistem Gastrointestinal. Jakarta :Trans Info Media

Setiadi (2013) Konsep dan Praktik Penulisan Riset Keperawatan.Yogyakarta : Graha Ilmu

Swarjana, I. K. (2012) Metodologi Penelitian Kesehatan. Yogyakarta : CV Andi Offset.

Widiya T., Marul, \& Rahmah B., (2018) Hubungan Pola Makan dan Tingkat Stres terhadap Kekambuhan Gastritis di Wilayah Kerja Puskesmas Tarok Kota Payakumbuh Tahun 2017.Padang : Jurnal Kesehatan Andalas

Wijoyo, M.P (2009) 15 Ramuan Penyembuh Gastritis. Jakarta : Bee Media Indonesia 
